\title{
Effects of Local Vibration on Bone Loss in Tail-Suspended Rats
}

\author{
Authors \\ Affiliation

\section{L.-w. Sun, H.-q. Luan, Y.-f. Huang, Y. Wang, Y.-b. Fan} \\ Key Laboratory for Biomechanics and Mechanobiology of Ministry of Education, School of Biological Science and Medical \\ Engineering, Beihang University, Beijing, China
}

Key words
local vibration
bone
microstructure
tendon
muscle

accepted after revision September 16, 2013

\section{Bibliography \\ DOI http://dx.doi.org/ 10.1055/s-0033-1358468 Published online: \\ April 15, 2014 \\ Int J Sports Med 2014; 35 : 615-624 @ Georg Thieme Verlag KG Stuttgart · New York ISSN 0172-4622}

\section{Correspondence}

\section{Prof. Yu bo Fan}

Key Laboratory for Biomechanics and Mechanobiology of Ministry of Education School of Biological Science and Medical Engineering Beihang University No. 37

Xueyuan Road Haidian district Beijing 100191

China

Tel.: $+86 / 10 / 82339428$

Fax: $+86 / 10 / 82339428$

yubofan@buaa.edu.cn

\section{Abstract \\ $\nabla$}

We investigated the effects of vibration $(35 \mathrm{~Hz}$, $45 \mathrm{~Hz}$ and $55 \mathrm{~Hz}$ ) as countermeasure locally applied to unloading hind limbs on bone, muscle and Achilles tendon. 40 female Sprague Dawley rats were divided into 5 groups $(\mathrm{n}=8$, each): tailsuspension (TS), TS plus $35 \mathrm{~Hz} / 0.3 \mathrm{~g}$ vibration (TSV35), TS plus $45 \mathrm{~Hz} / 0.3 \mathrm{~g}$ vibration (TSV45), TS plus $55 \mathrm{~Hz} / 0.3 \mathrm{~g}$ vibration (TSV55) and control (CON). After 21 days, bone mineral density (BMD) and the microstructure of the femur and tibia were evaluated by $\mu \mathrm{CT}$ in vivo. The biomechanical properties of the femur and Achilles tendon were determined by a materials testing system. Ash weight of bone, isotonic contraction and wet weight of soleus were also inves-

\section{Introduction \\ $\nabla$}

Spaceflight has been shown to cause loss in bone mass and strength and muscle atrophy $[5,14]$, Simulated microgravity caused a decrease in tendon stiffness in the Achilles tendon $[3,33]$. This may seriously affect astronaut performance and increases the risk of injury in space [28]. Bone loss is one of the highest risk factors during long spaceflight. Bone mineral density decreases at an average rate of about $1 \%$ per month within the early period in space [25]. Moreover, bone demineralization continues throughout the duration of such unloading stimulus [23]. Therefore, it is important to preserve the musculoskeletal system conditioning of astronauts in spaceflight.

Treadmill, cycle ergometer and interim resistance exercise have been applied on the International Space Station to counter bone loss and muscle atrophy [9]. However, bone loss cannot be fully prevented despite astronauts spending about $2.5 \mathrm{~h}$ per day on training $[7,45]$. In addition to exercise training for preventing bone loss, tigated. $35 \mathrm{~Hz}$ and $45 \mathrm{~Hz}$ localized vibration were able to significantly ameliorate the decrease in trabecular BMD (expressed as the percentage change from TS, TSV35: 48.11\%, TSV45: $31.09 \%$ ), microstructure and ash weight of the femur and tibia induced by TS. Meanwhile, $35 \mathrm{~Hz}$ vibration significantly improved the biomechanical properties of the femur (57.24\% bending rigidity and $41.66 \%$ Young's modulus vs. TS) and Achilles tendon (45.46\% maximum load and 66.67\% Young's modulus vs. TS). Additionally, Young's modulus of the femur was highly correlated with microstructural parameters. Localized vibration was useful for counteracting microgravityinduced musculoskeletal loss. In general, the efficacy of $35 \mathrm{~Hz}$ was better than $45 \mathrm{~Hz}$ or $55 \mathrm{~Hz}$ in tail-suspended rats.

studies have shown that high-frequency, lowamplitude whole-body vibration (WBV) prevented bone loss and the decrease in bone strength in both animals (rats and mice) $[15,31,37,47]$ and humans $[18,19]$. The highfrequency vibration significantly prevented soleus muscle atrophy and improved the biomechanical properties of muscle tendon in animals (rats and mice) [26,38,48] and humans [43]. However, some studies have found that WBV might cause discomfort or be deleterious to the peripheral vasculature of mice [30] and humans [24]. Additionally, the effects of WBV depended on not only the frequency of vibration [32] but also the posture of body in mice [8] and humans $[2,35]$.

On the other hand, studies have suggested that the mechanisms of mechanically adaptive bone modeling and remodeling were local responses in rats or mice $[1,12,16,17,39,44,51]$. Wenger [47] found that the forelimb was unaffected by WBV even though WBV could improve femoral bone density in mice. More importantly, bone 
loss of astronauts during spaceflight and persons with spinal cord injury has occurred primarily in the lower limbs and trunk. Therefore, we believe that local vibration would be better than WBV for combating osteoporosis, especially in space.

To prove whether local vibration can counteract the deterioration of musculoskeletal system under microgravity, we investigated the effects of different frequencies of vibration $(35 \mathrm{~Hz}$, $45 \mathrm{~Hz}$ and $55 \mathrm{~Hz}$ ) on microgravity-induced bone loss, muscle and Achilles tendon atrophy using a custom-made training device which applied vibration locally on hind limbs in tail-suspended rats. This study will be helpful not only in developing an efficient countermeasure against space-induced osteoporosis but also for understanding the mechanism of vibration on preventing osteoporosis and improving exercise training efficiency.

\section{Materials and Methods}

$\nabla$

\section{Experimental animals and animal care}

Female 8-week old Sprague Dawley rats were purchased from the Experimental Animal Center of Beijing University (body weight ranged 175-195g) and were subjected to the same housing conditions with 12-h dark-light cycles and food and water ad libitum for 21 days in the animal facility of our Department at Beihang University, China. Animal treatment and care conformed to the Regulations for the Administration of Affairs Concerning Experimental Animals pursuant to Decree No. 2 of the State Science and Technology Commission of China and the Guiding Principles for the Care and Use of Animals approved by the Beijing Government. The study meets the ethical standards of the journal [20]. All protocols were approved by the Animal Care Committee of Beihang University.

After 7 days of adaptation in standard laboratory cages $(n=2$, each cage), 40 specimens were randomly divided into five groups $(n=8$, each): tail-suspension (TS), tail-suspension plus vibration exercise at $35 \mathrm{~Hz}$ (TSV35), tail-suspension plus vibration exercise at $45 \mathrm{~Hz}$ (TSV45), tail-suspension plus vibration exercise at $55 \mathrm{~Hz}$ (TSV55) and control (CON). In TS, TSV35, TSV45 and TSV55 rats were subjected to tail suspension for a duration of 21 days, thus simulating weightlessness as previously reported [29]. In addition, TSV35, TSV45 and TSV55 rats were treated by vibration with a custom made TS-rat training device designed in our laboratory ( $\bullet$ Fig. 1). On the device, the rats could engage in vibration exercise during hind limb unloading without harm, and hind limbs were subjected to vertical vibration loading. The rats were awake when vibration training was performed. The vibration treatment was administered twice a day (at 9 a.m. and 5 p.m.) for about 4 min each time.

\section{Bone mineral density (BMD) and microstructure were measured by $\mu \mathrm{CT}$}

At the end of experiment (day 22), rats were anaesthetized with $1 \%$ pentobarbital sodium $(6 \mathrm{ml} / \mathrm{kg}$, i.p.) for in vivo scan by $\mu \mathrm{CT}$ (SkyScan1076, Belgium). The distal femurs and proximal tibia of rats were scanned as previously reported [41]. Briefly, all scans were performed at the following settings: $70 \mathrm{kV}$ X-ray voltage, $143 \mu \mathrm{A}$ current, $1 \mathrm{~mm}$ aluminum filter, $18 \mu \mathrm{m}$ pixel size, $360^{\circ}$ tomographic rotation and a rotation step of $0.6^{\circ}$. The measured region started at the position of $1.898 \mathrm{~mm}$ to the growth plate level and extended to the diaphysis, covering a total length of $4.745 \mathrm{~mm}$. All scans were reconstructed with the same parameters. The region of interest was delineated by freehand drawing
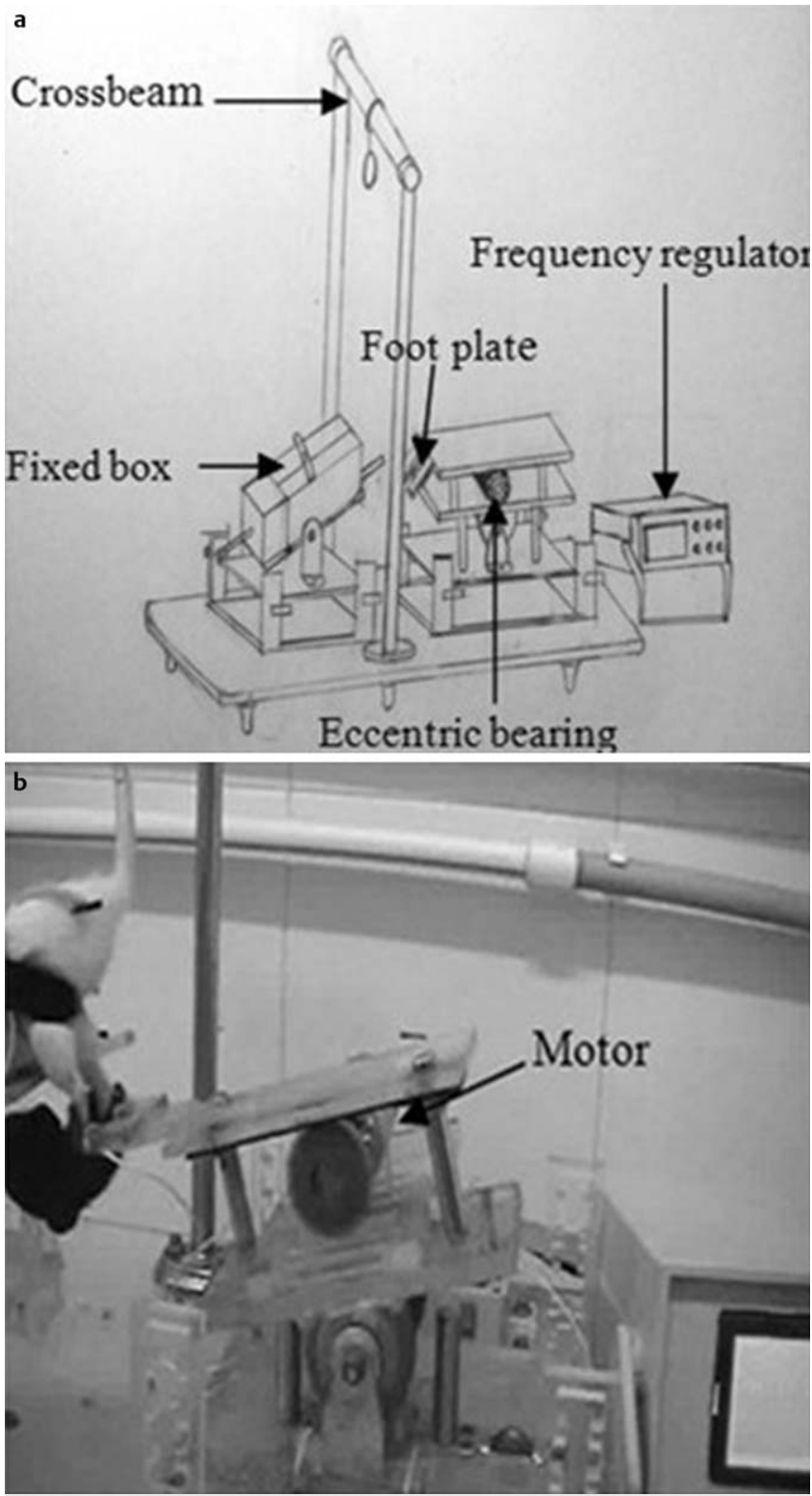

Fig. 1 a Diagram of custom-made vibration training device for the tail-suspended (TS)-rat $\mathbf{b}$ Photograph showing TS-rat during exercise on the device in the laboratory. The rat's trunk was placed in a fixed box $\left(30^{\circ}\right.$ angle) and hind paws were fixed by adhesives on the stepper footplates. When vibration training was performed, training was initiated by a motor connected to an eccentric bearing.

from the same investigator, then BMD and the trabecular microstructural parameters of both distal femur and proximal tibia were calculated, including 1) BV/TV (Percent bone volume), 2) BS/BV (Bone surface/Bone volume), 3) Tb.Th (Trabecular thickness), 4) Tb.Sp (Trabecular separation), 5) Tb.N (Trabecular number) and 6) SMI (Structure model index). In addition, crosssectional area (CSA) of rat whole calf muscles was calculated at $4.745 \mathrm{~mm}$ to the growth plate.

\section{Isotonic contraction and wet weight of soleus}

After the $\mu \mathrm{CT}$ scan, the soleus of right hind limb was immediately exposed without damage to its main arteries and veins in vivo. The distal tendon of soleus was separated from bone and then was attached to tension sensor by low elastic line. The proximal soleus was still attached with bone in vivo. Then the 

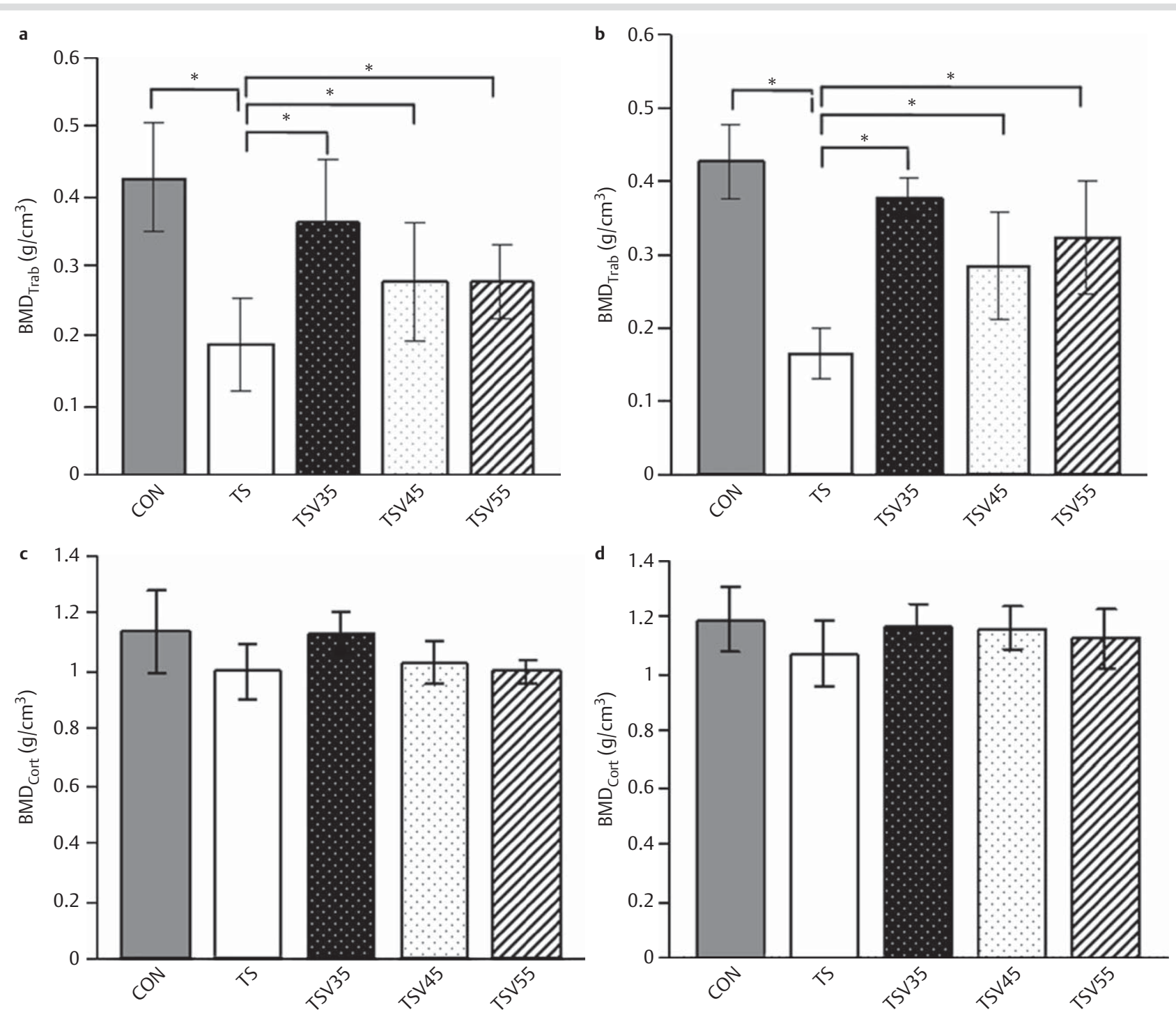

Fig. 2 a Trabecular BMD of femur by $\mu C T^{*} p<0.05$ b Trabecular BMD of tibia by $\mu C T^{*} p<0.05$ c Cortical BMD of femur by $\mu C T$ d Cortical BMD of tibia by $\mu \mathrm{CT}$.

contractive function of soleus was measured by RM6240 multichannel physiological signal acquisition decency (force sensor range: $0-50 \mathrm{~g}$, sensitivity: $0.1 \mathrm{~g}$; Chengdu instrument factory, Chengdu, China). Briefly, $2 \mathrm{Ag}-\mathrm{AgCl}$ electrodes were placed on the soleus belly. The soleus was stimulated by a square wave with $900 \mu$ s pulse width and an amplitude of $4 \mathrm{~V}$ [10] on RM6240 multi-channel physiological signal acquisition decency. Before single and tetanic stimulation, the soleus was adjusted to the optimal initial length. Single stimulation used a square wave, while tetanic stimulation was a square wave string. Next, five single contraction and tetanic contraction waveforms were recorded. During the experiment, the soleus was constantly dipped into the Ringer solution to keep the muscle fibers alive. Following euthanization, the tendons of the triceps surae were excised, and the weight of soleus and gastrocnemius dried by filter paper were ascertained on a Sartorius electronic balance (precision: $0.1 \mathrm{mg}$; Sartorius AG, Goettingen, Germany).
Measurement of biomechanical properties of femur through 3-point bending test

Following the in vivo measures as described above, rats were euthanized with narcotic overdose ( $1 \%$ pentobarbital sodium, $18 \mathrm{ml} / \mathrm{kg}$, i.p.). The right femur of the rat hind limb was excised clean of soft tissues, wrapped in a saline-soaked gauze bandage and then preserved at $-20^{\circ}$ for the 3 -point bending test. The three-point bending of femur in the mediolateral direction was carried out on a Shimadzu AG-10KNIS testing machine as previously reported [40]. Briefly, the span was approximately $20 \mathrm{~mm}$. The specimen was preconditioned for 5 cycles of loading $(10 \mathrm{~N})$, which were applied on the medial surface of the femur at a rate of $0.1 \mathrm{~mm} / \mathrm{min}$. The bending load was applied at a rate of $0.1 \mathrm{~mm} /$ min until failure of the specimen. The maximum load (Max load), break load, stiffness, bending rigidity and Young's modulus of the femoral mid shaft were determined and calculated.

\section{Ash weight}

The left femur and tibia of the rat hind limb were excised clean of soft tissues and treated using a modified version of the method previously described [21]. Specifically, bones were 


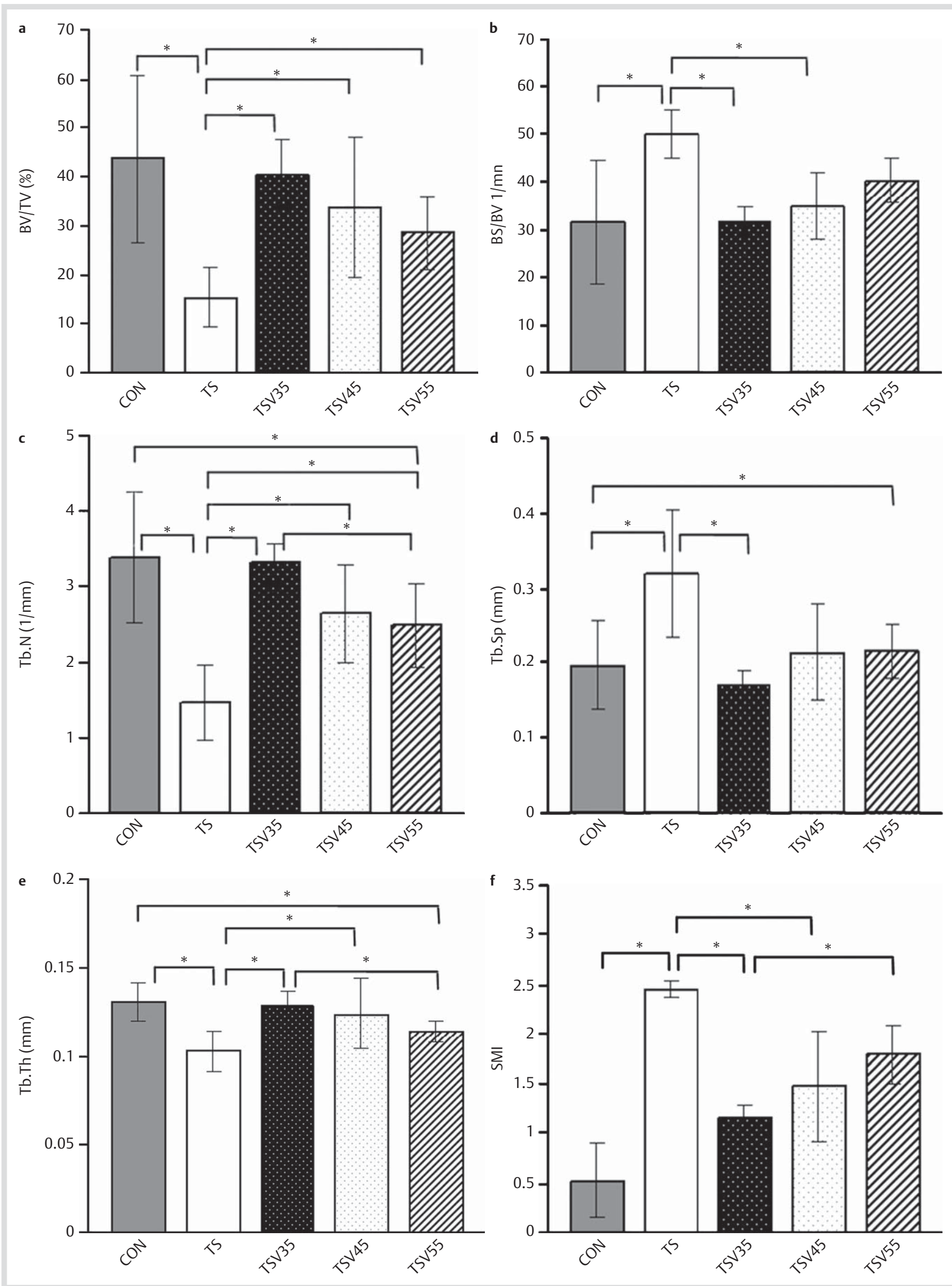

Fig. 3 a Trabecular microstructural parameter (BV/TV) of femur by $\mu \mathrm{CT}^{*} \mathrm{p}<0.05$ b Trabecular microstructural parameter (BS/BV) of femur by $\mu C T^{*}$ $p<0.05$ c Trabecular microstructural parameter (Tb.N) of femur by $\mu C T^{*} p<0.05$ d Trabecular microstructural parameter (Tb.Sp) of femur by $\mu C T^{*} p<0.05$ e Trabecular microstructural parameter (Tb.Th) of femur by $\mu \mathrm{CT}^{*} \mathrm{p}<0.05$ Trabecular microstructural parameter (SMI) of femur by $\mu C T^{*} \mathrm{p}<0.05$. 


\begin{tabular}{|c|c|c|c|c|c|c|}
\hline & CON & TS & TSV35 & TSV45 & TSV55 & Table 1 Trabecular microstruc- \\
\hline $\mathrm{BV} / \mathrm{TV}$ & $48.59 \pm 6.72^{*}$ & $10.74 \pm 3.75$ & $39.01 \pm 9.67^{*}$ & $33.38 \pm 7.63^{*} \&$ & $24.72 \pm 3.67^{*} \#$ & \\
\hline $\mathrm{BS} / \mathrm{BV}$ & $29.29 \pm 4.18^{*}$ & $48.31 \pm 4.17$ & $32.86 \pm 4.37^{*}$ & $35.40 \pm 4.35^{*}$ & $40.72 \pm 3.45$ & \\
\hline Tb.N & $3.32 \pm 0.84^{*}$ & $1.07 \pm 0.39$ & $3.08 \pm 0.55^{*}$ & $2.75 \pm 0.45^{*}$ & $2.22 \pm 0.25^{*}$ & \\
\hline Tb.Sp & $0.18 \pm 0.04^{*}$ & $0.43 \pm 0.21$ & $0.18 \pm 0.03^{*}$ & $0.20 \pm 0.02$ & $0.24 \pm 0.02 \# \&$ & \\
\hline Tb.Th & $0.12 \pm 0.02^{*}$ & $0.10 \pm 0.01$ & $0.13 \pm 0.01^{*}$ & $0.12 \pm 0.01^{*}$ & $0.11 \pm 0.01^{*}$ & \\
\hline SMI & $0.75 \pm 0.89^{*}$ & $2.48 \pm 0.16$ & $1.43 \pm 0.31^{*}$ & $1.68 \pm 0.34^{*}$ & $2.02 \pm 0.16^{*} \#$ & \\
\hline
\end{tabular}

Values are mean \pm SD. Statistical tests were performed with univariate analysis. ${ }^{*}$ indicates significant difference vs. TS, \#indicates significant difference vs. CON, \& indicates significant difference vs. TSV35 $(p<0.05)$

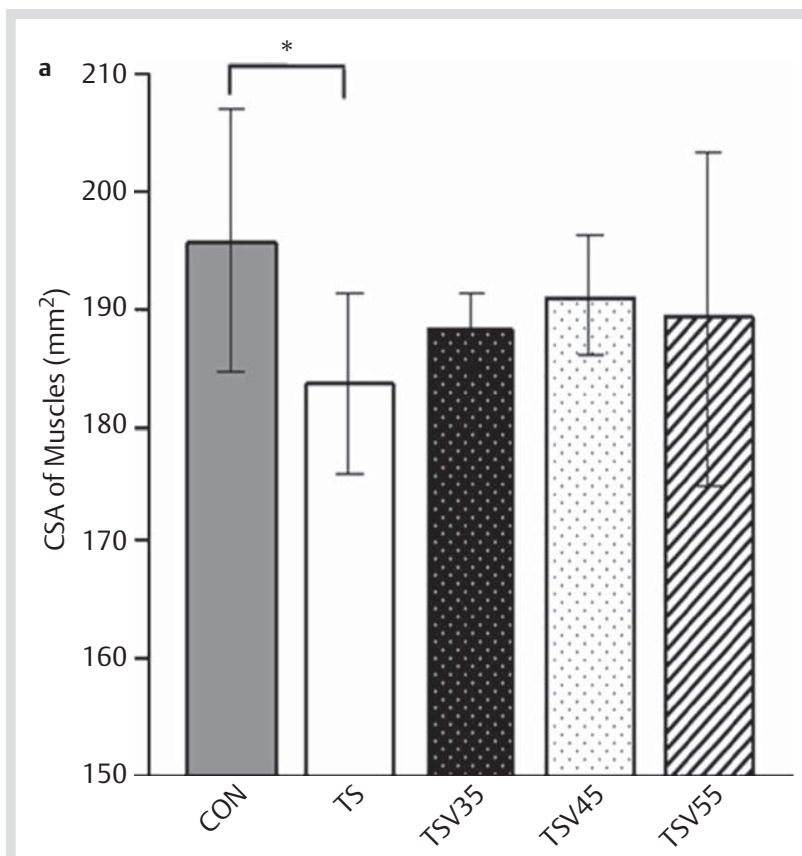

b

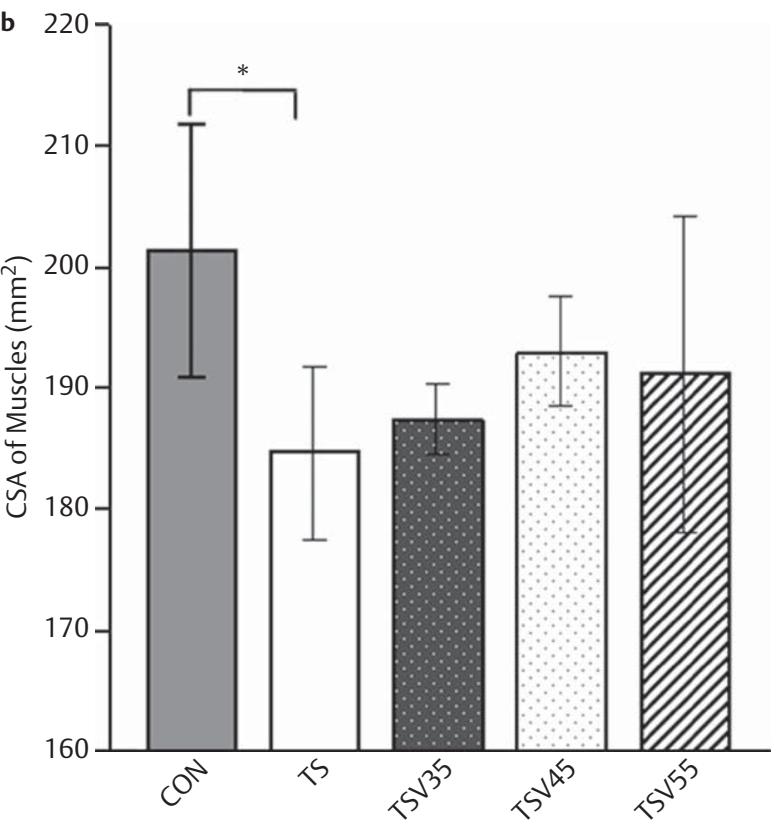

Fig. 4 a Cross-Sectional Area (CSA) of whole rat right calf muscle by $\mu C T^{*} p<0.05$ b Cross-Sectional Area (CSA) of whole rat left calf muscle by $\mu C T^{*} p<0.05$.

immersed in solvent (2 vol. chloroform: 1 vol. methanol) to extract fat for 5 days, then dried at $105^{\circ}$ in a drying oven for $36 \mathrm{~h}$ until weight was stable. Dry weight was measured when cooling. All specimens were burned to ash at $700^{\circ} \mathrm{C}$ in a muffle fur- nace for $24 \mathrm{~h}$. The ratio of ash weight was then calculated as AW\%=ash weight/dry weight $\times 100$.

\section{Tensile mechanical testing of tendons}

Following euthanization, the left Achilles tendon unit was dissected free from surrounding tissues, leaving the distal portion attached to the calcaneus. The tissues were subsequently wrapped in saline-soaked gauze and stored in a Cryovial at $-20^{\circ} \mathrm{C}$ until the day of testing. The cross-sectional area and length of the tendon were measured by means of digital image just before mechanical testing.

Tensile testing of the Achilles tendon was carried out on a materials testing system (AG-IS MO, Shimadzu, Japan). The specimen was preconditioned for 8 cycles of loading $(0-10 \mathrm{~N})$ at a rate of $3 \mathrm{~mm} / \mathrm{min}$. The tensile load was applied at a rate of $3 \mathrm{~mm} / \mathrm{min}$ until failure of the specimen. The maximum load (Max load), stiffness, break load, break stress, fracture deflection and Young's modulus of the specimen were determined and calculated.

\section{Statistical analysis}

All values were expressed as means \pm standard deviation (SD). Statistical analyses were performed with SPSS 13.0 using univariate analysis. Pearson correlation analyses were used to assess the correlation between biomechanical parameters and microstructural parameters of femur. The level of statistical significance was set at $\mathrm{p}<0.05$.

\section{Results}

$\nabla$

\section{BMD from $\mu \mathrm{CT}$}

As $\bullet$ Fig. 2 showed, trabecular BMD $\left(\mathrm{g} / \mathrm{cm}^{3}\right)$ of femur and tibia in the TS group decreased significantly compared with the CON, TSV35, TSV45 and TSV55 group, respectively, while there were no significant differences in the TSV35, TSV45 or TSV55 group compared to the CON group. There were no significant differences in cortical BMD $\left(\mathrm{g} / \mathrm{cm}^{3}\right)$ of femur and tibia among five groups.

\section{Trabecular bone microstructure from $\mu \mathrm{CT}$}

In the femur and tibia, BV/TV, Tb.N and Tb.Th decreased significantly in the TS group compared to the CON, TSV35 or TSV45 group, while BS/BV, Tb.Sp and SMI in the TS group increased significantly compared to the CON and TSV35 group. BV/TV and Tb.N in the TS group decreased significantly compared to the TSV55 group. For microstructural parameters (BV/TV, Tb.N, Tb. Th, BS/BV, Tb.Sp and SMI), there was no significant difference in the TSV35 or TSV45 group compared to CON group, while Tb.Sp increased significantly in the TSV55 group compared to the CON group ( $\bullet$ Fig. 3 and $\bullet$ Table 1 ). In addition, the CSA of whole calf muscles in the TS group decreased significantly compared to the CON group. For the CSA of whole calf muscles, there was no sig- 

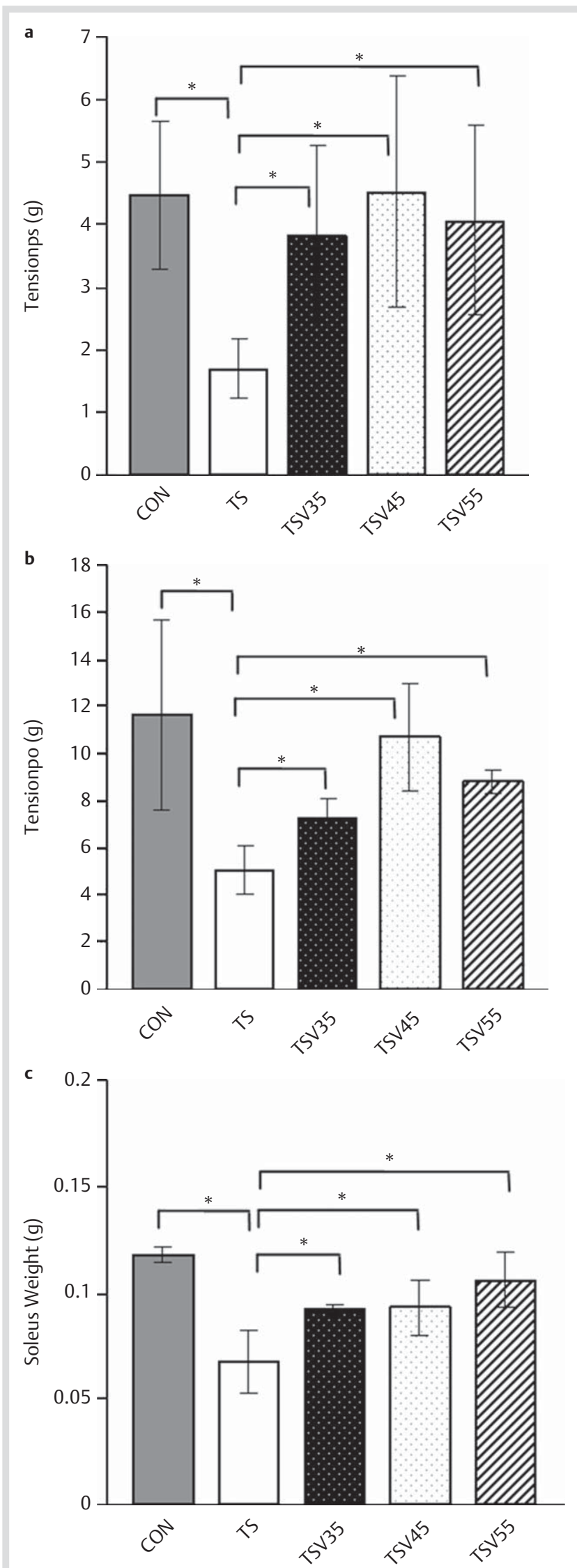

Fig. 5 a Contractile tension in soleus muscle, the peak twitch tension (tensionps) ${ }^{*} \mathrm{p}<0.05 \mathbf{b}$ Contractile tension in soleus muscle, maximum tetanic tension (tensionpo) ${ }^{*} p<0.05 \mathrm{c}$ Wet mass of soleus ${ }^{*} p<0.05$.

nificant difference in the TSV35, TSV45 and TSV55 group compared to the CON group ( $\odot$ Fig. 4 ).

\section{Contractile function and wet weight of soleus}

As $\odot$ Fig. 5 showed, the peak twitch tension (tension $n_{\mathrm{ps}}$ ), maximum tetanic tension (tension ${ }_{\mathrm{po}}$ ) and wet mass of the soleus (soleus weight) in the TS group were decreased significantly compared to the CON, TSV35, TSV45 and TSV55 group, respectively. No significant differences were found among the TSV35, TSV45 and TSV55 group compared to the CON group in the parameters (tension $_{\mathrm{ps}}$, tension $\mathrm{po}_{\mathrm{p}}$ and weight) of the soleus.

Ascertaining the biomechanical properties of the femur using 3 -point bending test

In the TS group, maximum load, break load, bending rigidity, stiffness and Young's modulus were significantly decreased compared to the CON and TSV35 group, while there were no significant differences between the TSV35 and CON group. In the TSV45 and TSV55 group, maximum load, bending rigidity and stiffness were significantly decreased compared to the CON group (० Fig. 6).

\section{Ash weight}

Ascertaining bone ash weight is used to assess the proportion of inorganic substances such as minerals vs. organic bone material. The ratio of ash weight (AW) of the left femur and tibia is shown in $\bullet$ Fig. 7. The TS group showed significantly lower values compared to the CON, TSV35 and TSV45 group. There was no significant difference in the TSV35, TSV45 or TSV55 group compared to the CON group.

\section{Correlation between biomechanical parameters and microstructural parameters of the femur}

Our results showed that biomechanical parameters (e.g. maximum load, break load and Young's modulus) were correlated with BMD and microstructural parameters of femurs. Furthermore, Young's modulus was highly correlated with not only trabecular BMD but also microstructural parameters. Similarly, maximum load and microstructural parameters (e.g. BV/TV, Tb.N, Tb.Th and SMI) were highly correlated, while there was low correlation between break load and microstructural parameters or BMD ( $\bullet$ Table 2$)$.

\section{Tensile testing of tendons}

In the TS group, Young's modulus, fracture deflection and break stress were decreased significantly compared to CON and TSV35 group. In the TSV55 group, break stress was significantly decreased compared to CON group. None of the calculated parameters showed any significant differences among the TSV35, TSV45 and CON groups ( $\odot$ Table 3 ).

\section{Discussion}

$\nabla$

Most studies demonstrated that high-frequency, low-amplitude vibration have a positive effect on rat trabecular bone $[6,22,36,37,42]$. Recent studies also suggested that vibration could be used to prevent skeletal fragility in populations at risk of spinal cord injury $[2,4]$. Moreover, the previous studies indicated that $30-60 \mathrm{~Hz}(0.1-2 \mathrm{~g})$ WBV was capable of preventing bone loss in human and animal models [32]. These data from human [19,34] and animal [49] models also showed that such 

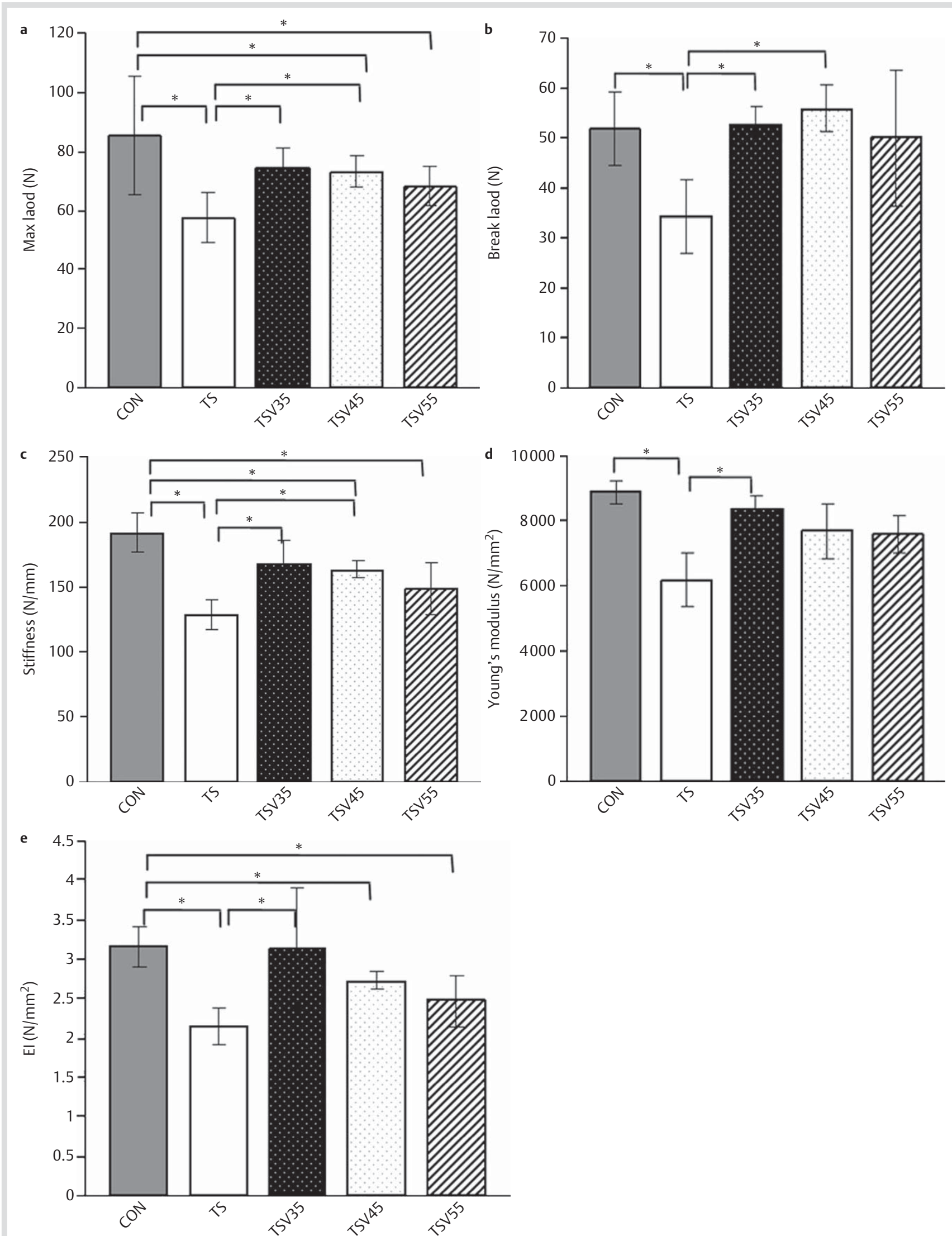

Fig. 6 a Biomechanical parameter (max load) of femur* $p<0.05$ b Biomechanical parameter (break load) of femur* $p<0.05$ c Biomechanical parameter (stiffness) of femur* $\mathrm{p}<0.05 \mathbf{d}$ Biomechanical parameter (Young's modulus) of femur* $\mathrm{p}<0.05$ e Biomechanical parameter (bending rigidity) of femur* $\mathrm{p}<0.05$. 
vibration stimulus could increase the bone mineral density and enhance the muscle force. Therefore, 35,45 and $55 \mathrm{~Hz}(0.3 \mathrm{~g})$ vibration were accordingly chosen in this study. Consistent with previous studies, this study showed that localize vibration of 35 ,

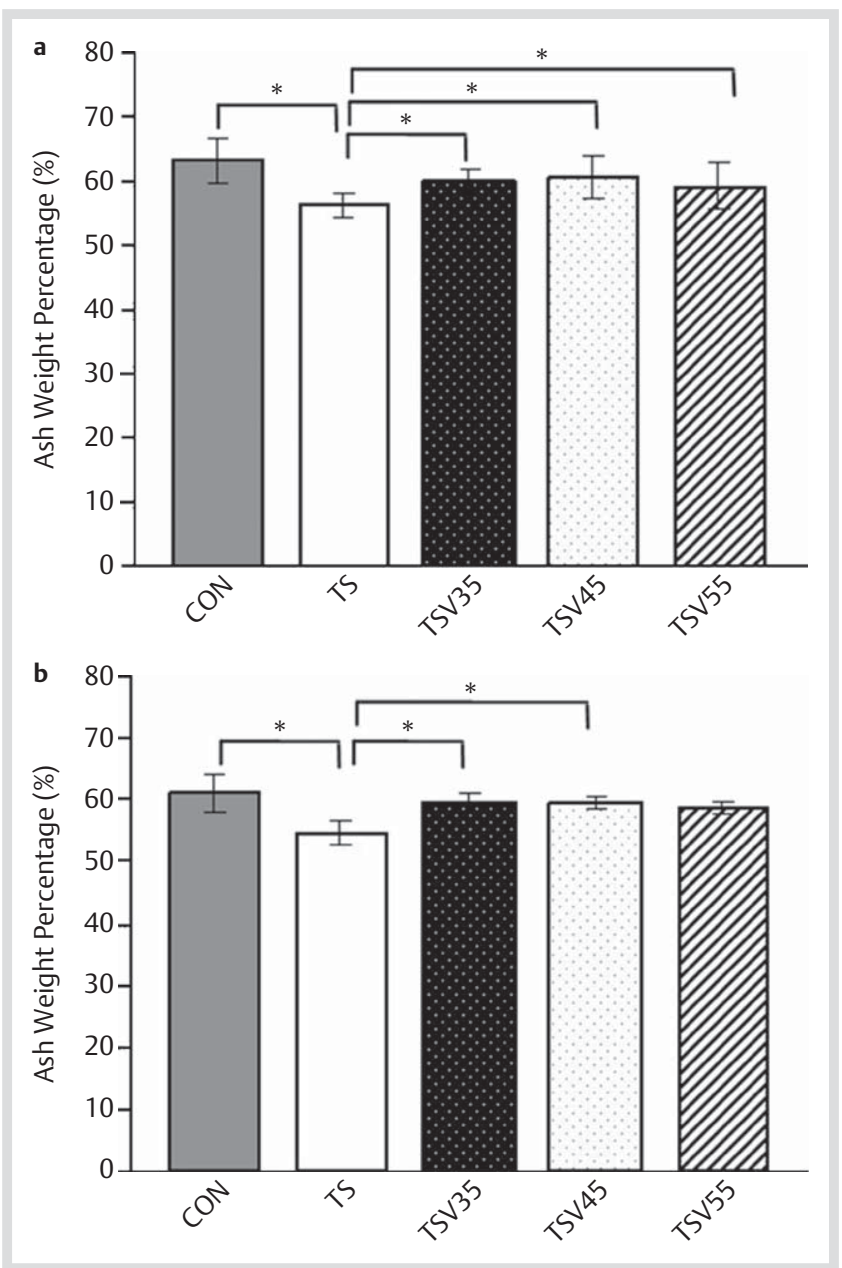

Fig. 7 a Ash weight percentage of left femur* $p<0.05$ b Ash weight percentage of left tibia* $\mathrm{p}<0.05$.

Table 2 Descriptive correlation coefficients $r$ of femur.

\begin{tabular}{|lclclcl} 
& $\begin{array}{l}\text { Maximum } \\
\text { load }\end{array}$ & $\mathbf{p}$ & $\begin{array}{l}\text { Break } \\
\text { load }\end{array}$ & $\mathbf{p}$ & $\begin{array}{l}\text { Young's } \\
\text { modulus }\end{array}$ & $\mathbf{p}$ \\
\hline BMD $_{\text {Trab }}$ & 0.66 & 0.011 & 0.45 & 0.097 & 0.82 & 0.000 \\
BMD $_{\text {Cort }}$ & 0.19 & 0.390 & 0.25 & 0.271 & 0.61 & 0.053 \\
\hline BV/TV & 0.70 & 0.002 & 0.49 & 0.069 & 0.89 & 0.000 \\
\hline Tb.N & 0.70 & 0.000 & 0.52 & 0.072 & 0.86 & 0.000 \\
\hline Tb.Th & 0.67 & 0.000 & 0.56 & 0.055 & 0.86 & 0.000 \\
Tb.Sp & -0.54 & 0.041 & -0.45 & 0.154 & -0.74 & 0.001 \\
\hline SMI & -0.72 & 0.000 & -0.49 & 0.068 & -0.83 & 0.000 \\
\hline
\end{tabular}

Pearson correlation analyses were used to assess the correlation
45 and $55 \mathrm{~Hz}$ could counteract the disuse-induced BMD decrease in trabecular bone resulting from the unloading of the hind limb. As for trabecular microstructure, it could be better preserved in unloaded hind limb through $35 \mathrm{~Hz}$ vibration than 45 or $55 \mathrm{~Hz}$.

Bone ash weight can be used to assess the proportion of inorganic substances. In our study, three vibration models were able to counteract the decrease of bone mineralization. For bone strength, our findings suggested that $35 \mathrm{~Hz}$ of vibration was better than 45 or $55 \mathrm{~Hz}$ in preventing the deterioration of bone biomechanical properties induced by TS. Moreover, biomechanical parameters and microstructural parameters were closely related, which proved that not only BMD but also microstructure could affect the biomechanical properties of bone. These findings supported previous studies that the microstructural parameters could be used to predict the biomechanical properties of trabecular bone $[11,46]$. Meanwhile, the microstructural parameters also might be used to predict the effects of microgravity on biomechanical properties of bone.

There has been some research on the effects of vibration on the hind limb muscles. In some studies, the dry defatted weight of the soleus and the gastrocnemius were not influenced by WBV in the ovariectomy rats [31], and WBV at $45 \mathrm{~Hz}(0.3 \mathrm{~g})$ decreased capillarity in the soleus of mouse [30]. However, Xie et al. found that WBV at $45 \mathrm{~Hz}$ could significantly increase the cross-sectional area and muscle fiber number of the soleus in rats [48]. Yang et al. found that high-frequency WBV could counteract the changes in expression of myosin heavy chain in intrafusal and extrafusal fibers in the rat soleus under weightlessness [50]. Our study showed that local vibration at 35,45 and $55 \mathrm{~Hz}$ could counteract the decrease not only in soleus weight but also the soleus contractile strength of rats subjected to tail suspension. The Achilles tendon can withstand high tension generated by muscle contraction and transmit the muscle contractile strength to drive the joint activities, which is important for maintaining normal movements. Weightlessness, disuse and other factors have attenuated the biomechanical properties of The Achilles tendon in both rats [3,13] and human [33]. High-frequency vibration could improve the biomechanical properties of the Achilles tendon and prevent Achilles tendon injury induced by immobilization in rats $[27,38,43]$ or humans [43]. Sandhu's research additionally showed that WBV could improve the biomechanical properties of the tendon, while having no effect on the rat muscle [38]. Our findings support the aforementioned studies. In our study, $35 \mathrm{~Hz}$ vibration was better than 45 and $55 \mathrm{~Hz}$ on the biomechanical properties of Achilles tendon, although there were no marked differences among the frequencies on counteracting tail-suspension-induced muscle atrophy. The vibration-induced improvement in the biomechanical properties of this specific tendon may be attributed to factors other than muscle amelioration.

In general, this study suggests that localized high-frequency vibration on the hind limb is useful in counteracting muscu-

Table 3 Biomechanical parameters of the Achilles tendon.

\begin{tabular}{|c|c|c|c|c|c|}
\hline & CON & TS & TSV35 & TSV45 & TSV55 \\
\hline Maximum load $(\mathrm{N})$ & $29.43 \pm 14.9$ & $23.47 \pm 12.45$ & $31.48 \pm 7.16^{*}$ & $24.94 \pm 13.63$ & $23.52 \pm 10.34$ \\
\hline Break load (N) & $24.31 \pm 14.43$ & $16.37 \pm 11.37$ & $25.45 \pm 7.04$ & $18.89 \pm 9.64$ & $19.12 \pm 8.63$ \\
\hline Young's modulus (N/mm²) & $167.00 \pm 65.20^{*}$ & $84.12 \pm 13.48$ & $153.12 \pm 53.12^{*}$ & $110.62 \pm 22$ & $114.61 \pm 25.36$ \\
\hline Fracture deflection $\left(\mathrm{N} / \mathrm{mm}^{2}\right)$ & $3.18 \pm 2.94^{*}$ & $2.04 \pm 0.78$ & $2.41 \pm 0.25^{*}$ & $2.09 \pm 0.24$ & $2.31 \pm 0.39$ \\
\hline Break stress (mm) & $2.21 \pm 0.4^{*}$ & $1.4 \pm 0.12$ & $1.67 \pm 0.17^{*}$ & $1.74 \pm 0.14^{*}$ & $1.68 \pm 0.18^{*} \#$ \\
\hline
\end{tabular}

Values are mean \pm SD. Statistical tests were performed with univariate analysis. ${ }^{*}$ indicates significant difference vs. TS, \# indicates significant difference vs. CON ( $p<0.05$ ) 
loskeletal degeneration induced by tail suspension. Furthermore, localized vibration might be a promising countermeasure or alternative to exercise for preventing bone loss during extended space flight.

\section{Acknowledgements}

This work was funded by grants from the National Natural Science Foundation of China (No. 31170897) and Nationnal Basic Research Program of China (No. 2011CB710901). Conflicts of interest: The authors state that they have no conflicts of interests.

\section{References}

1 Akhter MP, Cullen DM, Pedersen EA, Kimmel DB, Recker RR. Bone response to in vivo mechanical loading in two breeds of mice. Calcif Tissue Int 1998; 63: 442-449

2 Alizadeh-Meghrazi M, Masani K, Popovic MR, Craven BC. Whole-body vibration during passive standing in individuals with spinal cord injury: effects of plate choice, frequency, amplitude, and subject's posture on vibration propagation. PM\&R 2012; 4: 963-975

3 Almeida-Silveira MI, Lambertz D, Perot C, Goubel F. Changes in stiffness induced by hindlimb suspension in rat Achilles tendon. Eur J Appl Physiol 2000; 81: 252-257

4 Asselin P, Spungen AM, Muir JW, Rubin CT, Bauman WA. Transmission of low-intensity vibration through the axial skeleton of persons with spinal cord injury as a potential intervention for preservation of bone quantity and quality. J Spinal Cord Med 2011; 34: 52-59

5 Baldwin KM. Effect of spaceflight on the functional, biochemical, and metabolic properties of skeletal muscle. Med Sci Sports Exerc 1996; 28: 983-987

6 Castillo AB, Alam I, Tanaka SM, Levenda J, Li J, Warden SJ, Turner CH. Low-amplitude, broad-frequency vibration effects on cortical bone formation in mice. Bone 2006; 39: 1087-1096

7 Cavanagh PRGKO, Gopalakrishnan R, Kuklis MM, Maender CC, Rice AJ. Foot forces during exercise on the International Space Station. J Biomech 2010; 43: 3020-3027

8 Christiansen BA, Bayly PV, Silva MJ. Constrained tibial vibration in mice: a method for studying the effects of vibrational loading of bone. J Biomech Eng 2008; 130: 044502

9 Clément $\mathrm{G}$. The maintenance of physiological function in humans during spaceflight. Int J Sports Med 2005; 6: 185-198

10 Close $R$. Dynamic properties of fast and slow skeletal muscle of the rat during development. J Physiol 1964; 173: 74-95

11 Cory E, Nazarian A, Entezari V, Vartanians V, Muller R, Snyder BD. Compressive axial mechanical properties of rat bone as functions of bone volume fraction, apparent density and micro-ct based mineral density. J Biomech 2010; 43: 953-960

12 de Souza RL, Pitsillides AA, Lanyon LE, Skerry TM, Chenu C. Sympathetic nervous system does not mediate the load-induced cortical new bone formation. J Bone Miner Res 2005; 20: 2159-2168

13 Eliasson P, Fahlgren A, Pasternak B, Aspenberg P. Unloaded rat Achilles tendons continue to grow, but lose viscoelasticity. J Appl Physiol 2007; 103: 459-463

14 Fitts RH, Riley DR, Widrick JJ. Physiology of a microgravity environment invited review: microgravity and skeletal muscle. J Appl Physiol 2000; 89: 823-839

15 Flieger J, Karachalios T, Khaldi L, Raptou P, Lyritis G. Mechanical stimulation in the form of vibration prevents postmenopausal bone loss in ovariectomized rats. Calcif Tissue Int 1998; 63: 510-514

16 Fritton JC, Myers ER, Wright TM, van der Meulen MC. Loading induces site-specific increases in mineral content assessed by microcomputed tomography of the mouse tibia. Bone 2005; 36: 1030-1038

17 Fritton JC, Myers ER, Wright TM, van der Meulen MC. Bone mass is preserved and cancellous architecture altered due to cyclic loading of the mouse tibia after orchidectomy. J Bone Miner Res 2008; 23: 663-671

18 Gilsanz V, Wren TA, Sanchez M, Dorey F, Judex S, Rubin C. Low-level, high-frequency mechanical signals enhance musculoskeletal development of young women with low BMD. J Bone Miner Res 2006; 21: 1464-1474

19 Gusi N, Raimundo A, Leal A. Low-frequency vibratory exercise reduces the risk of bone fracture more than walking: a randomized controlled trial. BMC Musculoskelet Disord 2006; 7: 92
20 Harriss DJ, Atkinson G. Update - ethical standards in sport and exercise science research. Int J Sports Med 2011; 819-821

21 Joo YI, Sone T, Fukunaga M, Lim SG, Onodera S. Effects of endurance exercise on three-dimensional trabecular bone microarchitecture in young growing rats. Bone 2003; 33: 485-493

22 Judex S, Lei X, Han D, Rubin C. Low-magnitude mechanical signals that stimulate bone formation in the ovariectomized rat are dependent on the applied frequency but not on the strain magnitude. J Biomech 2007; 40: 1333-1339

23 Keyak JH, Koyama AK, LeBlanc A, Lu Y, Lang TF. Reduction in proximal femoral strength due to long-duration spaceflight. Bone 2009; 44: 449-453

24 Kiiski J, Heinonen A, Jarvinen TL, Kannus P, Sievanen H. Transmission of vertical whole body vibration to the human body. J Bone Miner Res 2008; 23: 1318-1325

25 Lang T, LeBlanc A, Evans H, Lu Y, Genant H, Yu A. Cortical and trabecular bone mineral loss from the spine and hip in long-duration spaceflight. J Bone Miner Res 2004; 19: 1006-1012

26 Legerlotz K, Schjerling $P$, Langberg $H$, Bruggemann GP, Niehoff A. The effect of running, strength, and vibration strength training on the mechanical, morphological, and biochemical properties of the Achilles tendon in rats. J Appl Physiol 2007; 102: 564-572

27 Leung KS, Shi HF, Cheung WH, Qin L, Ng WK, Tam KF, Tang N. Low-magnitude high-frequency vibration accelerates callus formation, mineralization, and fracture healing in rats. J Orthop Res 2009; 27: 458-465

28 McCrory JL, Baron HA, Balkin S, Cavanagh PR. Locomotion in simulated microgravity: gravity replacement loads. Aviat Space Environ Med 2002; 73: 625-631

29 Morey-Holton ER, Globus RK. Hindlimb unloading rodent model: technical aspects. J Appl Physiol 2002; 92: 1367-1377

30 Murfee WL, Hammett LA, Evans C, Xie L, Squire M, Rubin C, Judex S, Skalak TC. High-frequency, low-magnitude vibrations suppress the number of blood vessels per muscle fiber in mouse soleus muscle. J Appl Physiol 2005; 98: 2376-2380

31 Oxlund BS, Ortoft G, Andreassen TT, Oxlund H. Low-intensity, highfrequency vibration appears to prevent the decrease in strength of the femur and tibia associated with ovariectomy of adult rats. Bone 2003; 32: 69-77

32 Prisby RD, Lafage-Proust MH, Malaval L, Belli A, Vico L. Effects of whole body vibration on the skeleton and other organ systems in man and animal models: what we know and what we need to know. Ageing Res Rev 2008; 7: 319-329

33 Reeves ND, Maganaris CN, Ferretti G, Narici MV. Influence of 90-day simulated microgravity on human tendon mechanical properties and the effect of resistive countermeasures. J Appl Physiol 2005; 98: 2278-2286

34 Roelants M, Delecluse C, Verschueren SM. Whole-body-vibration training increases knee-extension strength and speed of movement in older women. J Am Geriatr Soc 2004; 52: 901-908

35 Rubin C, Pope M, Fritton JC, Magnusson M, Hansson T, McLeod K. Transmissibility of 15-hertz to 35-hertz vibrations to the human hip and lumbar spine: determining the physiologic feasibility of delivering low-level anabolic mechanical stimuli to skeletal regions at greatest risk of fracture because of osteoporosis. Spine (Phila Pa 1976) 2003; 28: 2621-2627

36 Rubin C, Turner AS, Muller R, Mittra E, McLeod K, Lin W, Qin YX. Quantity and quality of trabecular bone in the femur are enhanced by a strongly anabolic, noninvasive mechanical intervention. J Bone Miner Res 2002; 17: 349-357

37 Rubin $C, X u$ G, Judex $S$. The anabolic activity of bone tissue, suppressed by disuse, is normalized by brief exposure to extremely low-magnitude mechanical stimuli. FASEB J 2001; 15: 2225-2259

38 Sandhu E, Miles JD, Dahners LE, Keller BV, Weinhold PS. Whole body vibration increases area and stiffness of the flexor carpi ulnaris tendon in the rat. J Biomech 2011; 44: 1189-1191

39 Sugiyama T, Price JS, Lanyon LE. Functional adaptation to mechanical loading in both cortical and cancellous bone is controlled locally and is confined to the loaded bones. Bone 2010; 46: 314-321

40 Sun LW, Fan YB, Li DY, Zhao F, Xie T, Yang X, Gu ZT. Evaluation of the mechanical properties of rat bone under simulated microgravity using nanoindentation. Acta Biomater 2009; 5: 3506-3511

41 Sun LW, Wang C, Pu F, Li de Y, Niu HJ, Fan YB. Comparative study on measured variables and sensitivity to bone microstructural changes induced by weightlessness between in vivo and ex vivo micro-CT scans. Calcif Tissue Int 2011; 88: 48-53

42 Tan Ch, Ma Ch, Li Zhl KZ, Gong H, Zhang M, chen GSh. Study on $45 \mathrm{~Hz}$ whole body vibration in preventing the rats bone substances loss induced by tail suspended. Chin J Rehabil Med 2009; 24: 200-203 
43 Thomas Lapole CP. Effects of repeated Achilles tendon vibration on triceps surae stiffness and reflex excitability. J Electromyogr Kinesiol 2011; 21: 87-94

44 Torrance AG, Mosley JR, Suswillo RF, Lanyon LE. Noninvasive loading of the rat ulna in vivo induces a strain-related modeling response uncomplicated by trauma or periostal pressure. Calcif Tissue Int 1994; 54: 241-247

45 Trappe SCD, Gallagher P, Creer A, Peters JR, Evans H, Riley DA, Fitts $R H$. Exercise in space: human skeletal muscle after 6 months aboard the International Space Station. J Appl Physiol 2009; 106: 1159-1168

46 Ulrich D, van Rietbergen B, Laib A, Ruegsegger P. The ability of threedimensional structural indices to reflect mechanical aspects of trabecular bone. Bone 1999; 25: 55-60

47 Wenger KH, Freeman JD, Fulzele S, Immel DM, Powell BD, Molitor P, Chao YJ, Gao HS, Elsalanty M, Hamrick MW, Isales CM, Yu JC. Effect of whole-body vibration on bone properties in aging mice. Bone 2010; 47: 746-755
48 Xie L, Rubin C, Judex S. Enhancement of the adolescent murine musculoskeletal system using low-level mechanical vibrations. J Appl Physiol 2008; 104: 1056-1062

49 Yang $P$, Jia B, Ding C, Wang Z, Qian A, Shang P. Whole-body vibration effects on bone before and after hind-limb unloading in rats. Aviat Space Environ Med 2009; 80: 88-93

50 Yang $W$, Fan $X L, W u S D$, Song XA. Effects of high frequency vibration on expression of myosin heavy chain (MHC) in intrafusal and extrafusal fibers in soleus muscles of tail-suspended rats. Space Med Med Eng (Beijing) 2004; 17: 166-170

51 Zhang P, Tanaka SM, Jiang H, Su M, Yokota H. Diaphyseal bone formation in murine tibiae in response to knee loading. J Appl Physiol 2006; 100: $1452-1459$ 